\title{
The Prognostic Value of Pathologic Fractures in Patients with High-Grade Classic Osteosarcoma
}

\author{
Edward H.M. Wang, Claire Marie C. Durban and Ma. Victoria T. Serrano \\ University of the Philippines-Musculoskeletal Tumor Unit, \\ Department of Orthopedics, College of Medicine and Philippine General Hospital, University of the Philippines Manila
}

\begin{abstract}
Pathologic fracture in osteosarcoma has traditionally been associated with a poor prognosis and is an immediate indication for amputation of the affected extremity. This concept has been questioned and remains an area of debate, especially because advances in osteosarcoma treatment have today resulted in better survival and limb salvage rates.
\end{abstract}

It is the objective of this paper to analyze the survival and limb salvage rate of osteosarcoma patients presenting with pathologic fractures and compare these with the population of osteosarcoma patients without pathologic fractures.

Over a 15-year period (1993-2008), there were 84 patients presenting with non-metastatic high-grade classic osteosarcoma of the extremities (Enneking Stage IIB) who received complete treatment from the University of the Philippines-Musculoskeletal Tumor (UP-MuST) Unit and who had a follow up of at least 2 years. Ten of these 84 patients had pathologic fractures prior to surgery. Their overall survival was $50 \%$, similar to the $50.38 \%$ overall survival of the entire group of 84 osteosarcoma patients. Limb salvage rate was $60 \%$, similar to the $59 \%$ rate of patients without pathologic fractures.

This study shows that contrary to traditional teaching, overall survival for this subset of osteosarcoma patients with pathologic fractures is acceptable at $50 \%$ and is equal to that of the entire group of osteosarcoma patients. At the same time, successful limb salvage surgery is possible despite the presence of a pathologic fracture, especially in patients with good response to chemotherapy.

Key Words: pathologic fractures, osteosarcoma, limb salvage surgery

\section{Introduction}

Pathologic fracture occurs in 5-10\% of osteosarcoma patients. ${ }^{1}$ Until recently, the presence of a pathologic fracture was considered a poor prognostic factor for survival and management was immediate amputation, pathologic

Corresponding author: Edward H.M. Wang, MD, MSc

Department of Orthopaedics

Philippine General Hospital

University of the Philippines Manila

Taft Avenue, Ermita, Manila, 1000 Philippines

Telephone: +6325548466

Email: ewang@pldtdsl.net fractures being considered a contraindication to limb salvage. ${ }^{2,3,4}$ Over the past three to four decades, medical advances, especially in chemotherapy and surgery, have resulted in markedly improved overall survival and limb salvage rates for this otherwise uniformly fatal disease. ${ }^{1,4,5}$ However, treatment is modified according to certain tumor characteristics which have been implicated in the prognostication of osteosarcoma. These include tumor size, location, local extent, presence of metastasis, tumor marker levels, and presence of pathologic fracture. Of these variables, the presence of a pathologic fracture remains controversial as to whether or not it is indeed a poor prognostic factor. ${ }^{2,3,4,6-11}$

Results from literature have not been consistent. Earlier studies have suggested that the presence of a pathologic fracture heralded a poor overall outcome. ${ }^{2,3,4}$ It was theorized that when a fracture occurs through diseased bone, the hyperemia and fracture hematoma can result in hematogenous spread of cancer cells to the rest of the body. Based on such a theory, patients with pathologic fractures then were treated not only with a different chemotherapeutic protocol but also with amputation rather than limb saving surgery for fear of further contamination. Recent studies have, however, shown that such a poor outcome may be untrue. Overall survival and disease-free intervals have been reported to be statistically similar for patients with and without pathologic fractures. ${ }^{6-10}$ Amputation and a shift to a more complicated and oftentimes more expensive chemotherapy protocol may therefore be unnecessary.

In the Philippines, the Philippine General Hospital is one of the main referral centers for patients with osteosarcoma. It is the objective of this study to investigate the outcomes of osteosarcoma patients presenting with pathological fractures and compare this subset of patients with the general osteosarcoma population in terms of local and systemic recurrence and overall survival.

\section{Methods}

The study was undertaken at the University of the Philippines-Philippine General Hospital (UP-PGH). Study population included patients with non-metastatic highgrade classic intramedullary osteosarcoma of the extremities 
(Enneking Stage IIB) who presented with a pathologic fracture or who developed a pathologic fracture during preoperative chemotherapy, and who received complete treatment from the University of the PhilippinesMusculoskeletal Tumor (UP-MuST) Unit.

The study included patients of the UP-MuST Unit between January 1993 and December 2007 who had classic non-metastatic high-grade osteosarcoma of the long bones with no evidence of metastasis on presentation or diagnosis; no history of other cancers and no prior treatment elsewhere. They must have had complete treatment by the UP-MuST Unit with a follow up of at least 2 years or until death. Those who did not undergo standard chemotherapy for osteosarcoma or who refused standard treatment for osteosarcoma (limb salvage/amputation/metastasectomy) were excluded from the study. Those who had less than 2 years of follow up were likewise excluded from the study.

Each patient had a data sheet that served as a patient record at the tumor outpatient clinic. The tumor was described according to size, location, histologic subtype and grade. The patient's treatment profile included agents used for neo-adjuvant and adjuvant chemotherapy and the number of cycles of each course. The type of surgical intervention, limb-salvage surgery (LSS) or amputation, the date performed and the tumor necrosis percentage, graded according to Huvos'12 system, were logged into the data sheet. The presence of a pathologic fracture was noted; however, the exact time of occurrence of the fracture could not be determined. The patients' current status was categorized as alive, no evidence of disease (ANED), alive with evidence of the disease (AWED), died of disease (DOD), or died of complications (DOC).

\section{Results}

After excluding patients who already had metastasis at presentation, those who did not have preoperative or neoadjuvant chemotherapy, those patients who did not complete treatment, and those with less than 2 years of follow up, we had a total of 84 patients, 10 of whom had pathologic fractures. Table 1 compares the subgroup of patients with pathologic fractures (10) with those without pathologic fractures (74).

\section{Age}

The ages of the patients with pathologic fractures ranged from 9 to 15 years old, with a median of 12 years old. Those without pathologic fractures ranged from 4 to 57 years old, with a median age of 26.5 years. Although patients in this group were mostly between 18 and 24 years old, there were those in their 4 th, 5 th, and 6 th decades of life.

\section{Location}

Nine of the pathologic fractures occurred at the distal femur, while one involved the proximal humerus. None of the fractures occurred at the proximal tibia.
Of the 74 patients without pathologic fractures, 42 (57\%) were located in the femur, $19(26 \%)$ in the tibia and nine $(12 \%)$ in the proximal humerus. (Table 1$)$

Table 1. Comparison of patients with and without pathologic fractures

\begin{tabular}{|c|c|c|c|c|}
\hline \multirow{2}{*}{$\begin{array}{l}\text { Variable } \\
\text { Age (years) }\end{array}$} & \multicolumn{2}{|c|}{$\begin{array}{l}\text { Without pathologic } \\
\text { fractures }(\mathrm{N}=74)\end{array}$} & \multicolumn{2}{|c|}{$\begin{array}{c}\text { With pathologic } \\
\text { fractures }\end{array}$} \\
\hline & $4-57$ & $\begin{array}{c}\text { Median } \\
26.5\end{array}$ & $9-15$ & $\begin{array}{l}\text { Median } \\
12\end{array}$ \\
\hline \multicolumn{5}{|l|}{ Location } \\
\hline Humerus & 9 & $12.2 \%$ & 1 & $10 \%$ \\
\hline Distal radius and hand & 3 & $4.1 \%$ & 0 & 0 \\
\hline Femur & 42 & $56.8 \%$ & 9 & $90 \%$ \\
\hline Tibia & 19 & $25.7 \%$ & 0 & 0 \\
\hline Fibula & 1 & $1.4 \%$ & 0 & 0 \\
\hline \multicolumn{5}{|l|}{ Tumor Necrosis } \\
\hline$\geq 90$ & 24 & $32.4 \%$ & 6 & $60 \%$ \\
\hline$<90$ & 50 & $67.6 \%$ & 4 & $40 \%$ \\
\hline \multicolumn{5}{|l|}{ Surgical Intervention } \\
\hline LSS & 44 & $59.5 \%$ & 7 & $70 \%$ \\
\hline *subsequent amputation & 4 & $9.09 \%$ & 3 & $42.85 \%$ \\
\hline Amputation & 30 & $40.5 \%$ & 3 & $30 \%$ \\
\hline \multicolumn{5}{|l|}{ Histologic type } \\
\hline Chondroblastic & 16 & 21.6 & 1 & 10 \\
\hline Osteoblastic & 36 & 48.7 & 7 & 70 \\
\hline Fibroblastic & 12 & $16.2 \%$ & 2 & 20 \\
\hline Other histologic type & 10 & $13.5 \%$ & 0 & \\
\hline
\end{tabular}

LSS - Limb salvage surgery

\section{Tumor necrosis}

In patients with pathologic fractures, six (60\%) had excellent response to chemotherapy ( $\geq 90 \%$ tumor necrosis). The remaining four patients had tumor necrosis less than $90 \%$ with three having rates $\leq 50 \%$.

In those without pathologic fractures, 24 cases (32.4\%) had excellent response to chemotherapy; four of these cases had $100 \%$ tumor necrosis. The rest of the 50 patients had tumor necrosis $<90 \%$. (Table 1 )

\section{Type of surgery}

All 84 patients underwent surgical tumor excision with either a Limb salvage surgery (LSS) or an amputation. Among those with pathologic fractures, six (60\%) underwent LSS, three had an amputation and one underwent a Van Ness rotationplasty. Two of the six limb salvage patients eventually had to undergo an amputation because of skin necrosis and tumor recurrence. The patient who had a rotationplasty developed foot congestion secondary to failed venous repair and was amputated. In the remaining three patients with pathologic fractures, immediate amputation was undertaken because tumor size precluded LSS. Among the 74 patients without pathologic fractures, 44 underwent LSS $(59.5 \%)$ and four of them had to undergo an amputation because of local recurrence (3) or implant failure (1). (Table 1) 


\section{Histologic type}

Among the patients with pathologic fractures, seven $(70 \%)$ had an osteoblastic histology, one (10\%) was chondroblastic, and two (20\%) had a fibroblastic histology. This was similar to those without pathologic fractures where osteoblastic osteosarcoma was the most common subtype (49\%) (Table 1). Other histologic subtypes included telangiectatic, round cell and small cell variants.

\section{Tumor necrosis and type of surgery}

Six patients with pathologic fractures had tumor necrosis $\geq 90 \%$ : five underwent LSS although one of them had to eventually undergo an amputation because of skin flap necrosis. One patient with tumor necrosis $\geq 90 \%$ underwent an outright amputation because of the size of the lesion. Among the 74 patients without pathologic fractures with tumor necrosis $\geq 90 \%$, sixteen underwent LSS and eight had immediate amputations (Table 2).

\section{Discussion}

\section{Outcome}

Of the 10 osteosarcoma patients presenting with a pathologic fracture, five remain alive without evidence of the disease, while the other five have died because of the disease or its complications. The survival rate of $50 \%$ noted in this population is similar to the survival rate of $50.38 \%$ of the patients in the UP-MuST Unit. ${ }^{13}$ These results are comparable to survival rates reported in literature. $6,7,8,13,14,15$

\section{Location}

A previous study by Bramer et al. stated that the presence of a pathologic fracture is an independent predictor of poor survival. It was noted also that distally located fractures had detrimental effects on outcome compared to the proximally located fractures. ${ }^{4}$ However, Kim et al. in 2009 reported that pathologic fractures per se did not equate with a poorer survival rate. They concluded that tumor size and location confounded the presence of pathologic fractures, and these other factors instead had effects on the outcome: a large tumor size and proximally located tumors are associated with decreased metastasis-free survival rate. ${ }^{6}$
Most of the tumors in our population were in the lower limb, most commonly in the distal femur, with nine of the pathologic fractures occurring in this area. While the only pathologic fracture occurring in the proximal humerus resulted in death secondary to the disease, four (40\%) patients with distal femoral tumors also succumbed to the disease. Five $(50 \%)$ of those with distal femoral fractures are alive without evidence of the disease.

\section{Histologic type}

In the present study, the osteoblastic subtype was the most common histology noted both in the group of 74 as well as in the study population. This was followed by the chondroblastic and fibroblastic subtypes of osteosarcoma, which was a similar finding in the case-control study by Kim et al. However, authors noted no difference in survival among histotypes. ${ }^{6}$

\section{Type of surgery and outcome}

It has traditionally been taught that the presence of a pathologic fracture is a contraindication to LSS; only in recent studies has this concept been disputed. ${ }^{6-11}$

Among our 10 patients with pathologic fractures, six underwent limb salvage surgery although two of them had to eventually undergo amputation because of complications (skin necrosis and local recurrence). Limb saving surgery was undertaken as long as the tumor size had been either maintained or decreased with neoadjuvant chemotherapy, indicating a good response to chemotherapy. In our series, six out of 10 patients had tumor necrosis $\geq 90 \%$; five of these patients had limb salvage surgery and the sixth had a Van Ness rotationplasty. It would seem that limb salvage surgery is possible even in patients with pathologic fractures, especially in cases where tumor necrosis is $\geq 90 \%$.

Our data also shows that the presence of a pathologic fracture does not seem to be a poor prognostic factor. The overall survival rates of both populations in our study are comparable at $50 \%$. This rate is also comparable with the results of other studies (Table 3 ).

The results of this study agree with those of Kim in 2009 and Bacci in 2003 who reported that a pathologic fracture is not a significant prognosticator of poor overall survival rate

Table 2. Tumor necrosis and surgical intervention in those with and without pathologic fractures

\begin{tabular}{|c|c|c|c|c|c|c|c|}
\hline \multirow[b]{2}{*}{ Tumor Necrosis } & \multicolumn{3}{|c|}{ Without Fractures $(n=74)$ Type of Surgery } & \multicolumn{3}{|c|}{ With Fractures $(n=10)$ Type of Surgery } & \multirow[b]{2}{*}{ Rotation-plasty * } \\
\hline & $\begin{array}{l}\text { Amp } \\
n(\%)\end{array}$ & $\begin{array}{l}\text { LSS } \\
\text { n(\%) }\end{array}$ & $\begin{array}{l}\text { LSS } \rightarrow \text { Amp } \\
\text { n(\%) }\end{array}$ & $\begin{array}{l}\text { Amp } \\
\text { n(\%) }\end{array}$ & $\begin{array}{l}\text { LSS } \\
\text { n(\%) }\end{array}$ & $\begin{array}{l}\text { LSS } \rightarrow \text { Amp } \\
\text { n(\%) }\end{array}$ & \\
\hline $100 \%$ & $1(1.4)$ & $3(4.1)$ & 0 & 0 & 0 & 0 & $0(0)$ \\
\hline $90-99.9 \%$ & $7(9.5)$ & $13(17.56)$ & $1(7.7)$ & $1(10)$ & $5(50)$ & $1(20)$ & $0(0)$ \\
\hline $50-89.9 \%$ & $16(21.6)$ & $18(24.3)$ & $1(5.6)$ & 0 & $0(0)$ & $0(0)$ & $1(10)$ \\
\hline$<50 \%$ & $6(8.1)$ & $10(13.5)$ & $2(20)$ & $2(20)$ & $1(10)$ & $1(100)$ & $0(0)$ \\
\hline \multirow[t]{2}{*}{ Total } & 30 & 44 & 4 & 3 & 6 & & 1 \\
\hline & 74 & & & 10 & & & \\
\hline
\end{tabular}

* Patient who underwent rotationplasty had to have an amputation because of foot congestion

Amp-amputation; LSS -successful limb salvage surgery; LSS -> amp - limb salvage surgery with subsequent amputation 
in osteosarcoma patients (Table 4). However, studies with bigger populations are needed in order to make these conclusions with more confidence. A multinational, multicenter study is presently being undertaken by the East Asian Musculoskeletal Oncology Group (EAMOG), the research arm of the Asia Pacific Musculoskeletal Tumor Society.

Table 3. Outcomes of patients with and without pathologic fractures

\begin{tabular}{clll}
\hline & $\begin{array}{l}\text { ANED } \\
\mathbf{n}(\mathbf{\%})\end{array}$ & $\begin{array}{l}\text { DOD } \\
\mathbf{n}(\mathbf{\%})\end{array}$ & $\begin{array}{l}\text { DOC } \\
\mathbf{n}(\mathbf{\%})\end{array}$ \\
\hline Without fracture & $\mathbf{4 4}(\mathbf{5 9 . 4 6 )}$ & $\mathbf{3 4}(\mathbf{4 5 . 9 5 )}$ & $\mathbf{6} \mathbf{( 8 . 1 0 )}$ \\
LSS & $28(37.84)$ & $12(16.23)$ & $6(8.10)$ \\
Amp & $15(20.27)$ & $17(22.97)$ & 0 \\
LSS $\rightarrow$ Amp & $1(3.57)$ & $5(41.66)$ & 0 \\
With fracture & $\mathbf{5 ( 5 0 . 0 0 )}$ & $\mathbf{5 ( 5 0 . 0 0 )}$ & $\mathbf{0}$ \\
LSS & $3(60.00)$ & $1(20.00)$ & 0 \\
Amp & $2(40.00)$ & $1(20.00)$ & 0 \\
LSS $\rightarrow$ Amp & 0 & $3(60.00)$ & 0 \\
Rotationplasty & 0 & $1(10.00)$ & 0 \\
\hline
\end{tabular}

ANED -alive, no evidence of disease; DOD - died of disease; DOC - died of complications; LSS - successful limb salvage surgery; LSS -> amp - limb salvage surgery with subsequent amputation

Table 4. Survival, local recurrence, amputation rates in 5year studies

\begin{tabular}{|c|c|c|c|c|c|c|}
\hline \multirow{2}{*}{$\begin{array}{c}\text { Author/ } \\
\text { year }\end{array}$} & \multirow[t]{2}{*}{$\mathbf{N}$} & \multirow{2}{*}{$\begin{array}{c}\text { Fracture } \\
\text { atDx } \\
(\%)\end{array}$} & \multirow{2}{*}{$\begin{array}{l}\text { Amp } \\
\text { rate }\end{array}$} & \multirow{2}{*}{$\begin{array}{c}\text { LR } \\
\text { rate; } \\
\text { Amp } \\
\text { vs LSS }\end{array}$} & \multicolumn{2}{|c|}{ Survival } \\
\hline & & & & & $\begin{array}{c}\text { W } \\
\text { fracture }\end{array}$ & $\begin{array}{c}\text { W/o } \\
\text { fracture }\end{array}$ \\
\hline Kim & 37 & $25(68 \%)$ & $10.8 \%$ & $10.8 \%$ & $5-y r$ & \\
\hline \multirow[t]{3}{*}{2009} & & & & & MFSR & \\
\hline & & & & $0 \%$ vs & $48 \%$ & $62 \%$ \\
\hline & & & & $12 \%$ & & \\
\hline \multirow{3}{*}{$\begin{array}{l}\text { Bacci } \\
2003\end{array}$} & 46 & 46 & $23.9 \%$ & $4.3 \%$ & 5-YR & \\
\hline & & $(100 \%)$ & & & DFSR & \\
\hline & & & & $\begin{array}{c}9 \% \text { vs } \\
2 \%\end{array}$ & $59 \%$ & $61 \%$ \\
\hline
\end{tabular}

\section{Summary}

Of 10 patients with pathologic fractures, 50\% are alive with no evidence of disease. This survival rate is similar to that of the overall survival rate of osteosarcoma in the UPPGH (50\%). In contrast to traditional teaching that pathologic fractures require amputation and that pathologic fractures herald a poor outcome, it would seem that successful limb saving surgery is possible despite the presence of a pathologic fracture, especially when tumor necrosis is good.

\section{References}

1. Jaffe N, Spears R, Eftekhari F, et al. Pathologic fracture in osteosarcoma. Impact of chemotherapy on primary tumor and survival. Cancer. 1987;59(4):701-9.

2. Scully SP, Ghert MA, Zurakowski D, Thompson R, Gebhardt M. Pathologic fracture in osteosarcoma: prognostic importance and treatment implications. J Bone Joint Surg Am. 2002;84-A(1):49-57.
3. Scully SP, Temple HT, O'Keefe RJ, Mankin HJ, Gebhardt M. The surgical treatment of patients with osteosarcoma who sustain a pathologic fracture. Clin Orthop Relat Res. 1996;(324):227-32.

4. Bramer JA, Abudu AA, Grimer RJ, Carter SR, Tillman RM. Do pathological fractures influence survival and local recurrence rate in bony sarcomas? Eur J Cancer. 2007;43(13):1944-51.

5. Simon MA, Nachman J. The clinical utility of preoperative therapy for sarcomas. J Bone Joint Surg Am. 1986;68(9):1458-63.

6. Kim MS, Lee SY, Lee TR, et al. Prognostic effect of pathologic fracture in localized osteosarcoma: a cohort/case-controlled study at a single institute. J Surg Oncol. 2009;100(3):233-9.

7. Bacci G, Ferrari S, Longhi A, et al. Nonmetastatic osteosarcoma of the extremity with pathologic fracture at presentation: local and systemic control by amputation or limb salvage after preoperative chemotherapy. Acta Orthop Scand. 2003;74(4):449-54.

8. Niu XH, Ding Y. [The surgical treatment and outcome of non-metastatic osteosarcoma of the extremity with pathologic fractures]. Zonghua Wai Ke Za Zhi. 2008;46(22):1730-3

9. Simon MA, Aschliman MA, Thomas N, Mankin HJ. Limb-salvage treatment versus amputation for osteosarcoma of the distal end of the femur. J Bone Joint Surg Am. 1986;68(9):1331-7.

10. Griffin AM, Mclaughlin C, Ferguson PC, Bell RS, Wunder JS. Outcome following presentation with a pathologic fracture in osteosarcoma. J Bone Joint Surg (Br). 2008;90-B(supp-I):87-8.

11. Dae-Geun Jeon. Prognostic effect of pathologic fracture in localized osteosarcoma. APJOH. 2010;2(1):131-6.

12. Wunder JS, Paulian G, Huvos AG, Heller G, Meyers PA, Healey JH. The histological response to chemotherapy as a predictor of the oncological outcome of operative treatment of Ewing Sarcoma. J Bone Joint Surg Am. 1998;80(7):1020-33.

13. Wang EHM, Fernando G, Goleta-Dy A, et al. Osteosarcoma treatment in a low income country, small successes against gargantuan odds. 2007. Unpublished.

14. Sutow WW, Gehan EA, Vietti TJ, Frias AE, Dyment PG. Multidrug chemotherapy in pulmonary treatment of osteosarcoma. J Bone Joint Surg Am.1976;58(5):629-33.

15. Spanier SS, Shuster JJ, Vander Griend RA. The effect of local extent of the tumor of prognosis in osteosarcoma. J Bone Joint Surg Am.1990;72(5):643-53. 